\title{
Comparison of Sevoflurane versus Propofol under Auditory Evoked Potential Monitoring in Female Patients Undergoing Breast Surgery
}

\author{
Hsiu-Pin Chen ${ }^{1}$, Ya-Hui Hsu ${ }^{1}$, Kuo-Chun Hua ${ }^{1}$, Chih-Chung Lin ${ }^{1}$, Yung-Feng Lo ${ }^{2}$, Huang-Ping Yu ${ }^{1}$
}

Background: General anesthesia is used for most major surgeries, and the most common side effects include headache, nausea, vomiting, and sore throat. Major breast surgery is associated with a high incidence of postoperative nausea and vomiting (PONV). We compared the postoperative nausea and vomiting of propofol-based total intravenous anesthesia (TIVA) and sevoflurane (SEVO) anesthesia under auditory evoked potential (AEP) monitoring in female patients undergoing breast surgery.

Methods: $\quad$ A total of 84 patients scheduled to undergo elective breast surgery from 1 to $4 \mathrm{~h}$ in duration from March 2011 to December 2011 were prospectively included in the study. All participants were randomly assigned to TIVA or SEVO group. The AEP index was maintained at 15-25. After completing the surgery, the duration of surgery, emergence time, and the side effects of PONV were recorded.

Results: Patient characteristics, intraoperative and postoperative data, and the amounts of intraoperative analgesic drugs used were not significantly different between the TIVA and SEVO groups. The incidence of PONV was significantly higher in the SEVO group than in the TIVA group (50\% and $14.3 \%$, respectively; $p<0.001$ ), and the total cost was significantly lower in the TIVA group than in the SEVO group (648 \pm 185 and $850 \pm 197$, respectively).

Conclusion: We observed that when compared with sevoflurane, propofol given for the maintenance of general anesthesia improves the postoperative patient well-being and reduces the incidence of PONV. Furthermore, total intravenous anesthesia with propofol resulted in significant cost reductions.

(Biomed J 2013;36:125-131)

\begin{abstract}
At a Glance Commentary
Scientific background of the subject

General anesthesia is used for most major surgeries, and the most common side effects include headache, nausea, vomiting, and sore throat. Besides that, major breast surgery is associated with a high incidence of postoperative nausea and vomiting (PONV).
\end{abstract}

\section{What this study adds to the field}

Using one or the other method with an objective monitor to reduce the incidence of PONV in patient undergoing breast surgery is lacking. Thus we compared with sevoflurane, propofol given for the maintenance of general anesthesia to improve the postoperative patient well-being and reduces the incidence of $\mathrm{PONV}$.

\section{Key words: auditory evoked potential, breast surgery, propofol, sevoflurane}

$\mathrm{G}$ eneral anesthesia is used for most major surgeries and J can affect the entire body, including the brain and reflex functions. The most common side effects include headache, nausea, vomiting, and sore throat. ${ }^{[1,2]}$ In current practice, both propofol for total intravenous (i.v.) anesthesia and sevoflurane for inhalational anesthesia are frequently administered for general anesthesia because of their pharmacological properties, including fast recovery after anesthesia. ${ }^{[3-7]}$ Pro-

From the ${ }^{1}$ Department of Anesthesiology, Chang Gung Memorial Hospital at Linkou, Chang Gung University College of Medicine, Taoyuan, Taiwan; ${ }^{2}$ Department of General Surgery, Chang Gung Memorial Hospital at Linkou, Chang Gung University College of Medicine, Taoyuan, Taiwan

Received: Feb. 14, 2012; Accepted: Jul. 16, 2012

Correspondence to: Dr. Huang-Ping Yu, Department of Anesthesiology, Chang Gung Memorial Hospital at Linkou. 5, Fushing St., Gueishan, Taoyuan 333, Taiwan (R.O.C.). Tel.: 886-3-3281200 ext. 3624; Fax: 886-3-3281200 ext. 2787; E-mail: yuhp2001@ @gmh.org.tw

DOI: $10.4103 / 2319-4170.113228$ 
pofol has been associated with a low incidence of postoperative nausea and vomiting (PONV), compared with inhaled anesthetics. ${ }^{[8]}$ Some studies suggest that propofol acts as an antiemetic when it is used to treat chemotherapy-induced emesis ${ }^{[0]}$ and PONV in subhypnotic doses. ${ }^{[10,11]}$

Major breast surgery is associated with a high incidence of PONV. ${ }^{[12]} \mathrm{A}$ previous study found that the incidence of nausea and vomiting is as high as $60 \%$ and that most of these symptoms occur after patients leave the postoperative care unit. ${ }^{[13]}$ Incidence rates of PONV in women are approximately two to three times greater than in men, ${ }^{[14]}$ and the severity of vomiting is also greater in women. ${ }^{[15]}$ Using one or the other method with an objective monitor to reduce the incidence of side effects such as PONV and quality of anesthesia in patient undergoing breast surgery is lacking.

We hypothesized that total i.v. anesthesia with propofol might reduce the incidence of PONV and improve patient well-being and satisfaction. This randomized, prospective study was designed to assess the effects of total i.v. anesthesia with propofol compared with inhalational anesthesia with sevoflurane on patients undergoing breast surgery. Postoperative well-being and major adverse events in the postoperative period were recorded.

\section{METHODS}

This trial was approved by the ethical review committee of Chang Gung Memorial Hospital (CGMHIRB no. 99-3537A3) in accordance with the 2008 Declaration of Helsinki, and informed consent was obtained from every patient prior to participation in the trial.

\section{Patients}

A total of 84 patients undergoing elective breast surgery from 1 to $4 \mathrm{~h}$ in duration between March 2011 and December 2011 were prospectively included in the study. Exclusion criteria were: (1) refusal or inability to provide informed consent, (2) age less than 20 years or more than 70 years, smoking status, (3) allergy to intravenous propofol, (4) pregnancy, (5) gastrointestinal disease, (6) a history of motion sickness or a previous episode of PONV, (7) had received any steroid or antiemetic medication within $24 \mathrm{~h}$ before surgery, (8) or an ASA grade equal to or greater than 3. Associated medical illnesses were graded according to the American Society of Anesthetists' Physical Status Classification (ASA grade).

\section{Study design}

\section{Randomization}

All participants were randomly assigned to the TIVA group (total intravenous anesthesia with propofol) or the SEVO group (inhalational anesthesia with sevoflurane) using a concealed allocation approach (computer-generated codes) utilizing opaque, sealed envelopes containing the randomization schedule. These envelopes were opened immediately before induction of anesthesia.

Personnel in the post-anesthesia care unit (PACU), including the physician on duty, remained blinded to the randomization. Intravenous lines and stopcocks were flushed with saline to remove any visible trace of propofol before transporting patients to the PACU. All patients received oxygen via oxygen mask for at least $30 \mathrm{~min}$ after arrival in the PACU. This served to camouflage the odor of residual sevoflurane in expired air.

Research nurses who made intraoperative and postoperative observations were not involved in the care-giving process. During the patients' stay in the PACU, the anesthesia record was kept in a sealed envelope to be opened only in case of emergency by the research nurse who had performed the intraoperative observations. Patients were blinded to the anesthetic technique at all times during the study.

\section{Intraoperative settings}

All patients were unpremedicated. Before induction of anesthesia, electrocardiography (ECG), pulse oximetry, and noninvasive blood pressure monitoring were applied and three A-Line ${ }^{\circledR}$ Auditory evoked potential (AEP) electrodes (Danmeter, Odense, Denmark) were positioned at the mid-forehead (+), left forehead (reference), and left mastoid (-). In the TIVA group, anesthesia was induced with $2 \mathrm{mcg} / \mathrm{kg}$ fentanyl, $2 \%$ lidocaine $(0.5 \mathrm{mg} / \mathrm{kg})$, and cisatracurium $(0.2 \mathrm{mg} / \mathrm{kg})$. Afterward, continuous infusion of propofol was begun by using a target-controlled infusion (TCI) system (Fresenius Orchestra Primea ${ }^{\circledR}$, Fresenius Kabi AG, Bad Homburg, Germany) with the plasma target set (plasma mode drive $=\mathrm{Cp}$ ) at $5.0 \mathrm{mcg} /$ $\mathrm{ml}$ in Schneider mode. When the patient lost consciousness, the trachea was intubated until the AEP index (AAI) decreased to 20 and mechanical ventilation was then started. The anesthesia was maintained using TCI with propofol and a gas flow of $0.51 / \mathrm{min}$ oxygen mixed with $0.51 / \mathrm{min}$ air. In the SEVO group, anesthesia was induced with $2 \mathrm{mcg} / \mathrm{kg}$ fentanyl, $2 \%$ lidocaine $(0.5 \mathrm{mg} /$ $\mathrm{kg})$, cisatracurium $(0.2 \mathrm{mg} / \mathrm{kg})$, and $2 \mathrm{mg} / \mathrm{kg}$ propofol. After the loss of consciousness, tracheal intubation was performed until the AAI decreased to 20. The anesthesia was maintained with SEVO in $11 /$ min oxygen mixed with air. Partial oxygen saturation $\left(\mathrm{SpO}_{2}\right)$, mean blood pressure (MBP), and heart rate (HR) were monitored and recorded at the preinduction (baseline), 1 min intervals during induction of anesthesia, and subsequently at 
5 min intervals throughout the anesthesia and recovery periods. HR was measured using a continuous lead type II ECG; MBP was measured noninvasively using an automatic oscillometer and $\mathrm{SpO}_{2}$ was measured by pulse oximetry. Respiratory monitors included respiratory rate (RR), $\mathrm{SpO}_{2}$, and end-tidal carbon dioxide by capnometry.

During maintenance of anesthesia, propofol and sevoflurane were adjusted continuously to keep the AAI between 15 and 25. Adverse hemodynamic responses of about 1 min duration were recorded and classified as "hypertension" (MBP $>20 \%$ above preoperative baseline value), "hypotension" (MBP $<60 \mathrm{mmHg}$ ), "tachycardia" (HR $>20 \%$ above preoperative baseline value), or "bradycardia" (HR $<50$ beats/min). The concentrations of propofol and sevoflurane were adjusted according to patient's vital sign and AAI value every $1 \mathrm{~min}$, when adverse hemodynamic responses happen. If the AAI was over 25 and associated with hypertension and tachycardia, it was initially treated by concentration of effect $(\mathrm{Ce})$ with $0.2 \mathrm{mcg} / \mathrm{ml}$ and $0.2 \%$ increments of propofol and sevoflurane, respectively. If two increments were unsuccessful, propofol and sevoflurane were increased by $0.5 \mathrm{mcg} / \mathrm{ml}$ and $0.5 \%$ increments, respectively, until the AAI was between 15 and 25 . Hypertension and tachycardia were treated with fentanyl (1 mcg/kg i.v.) if the AAI was in the set range. If fentanyl did not work, hypertension with normal sinus rhythm was treated with nicardipine $(10 \mu \mathrm{g} / \mathrm{kg})$ or hypertension with tachycardia was treated with labetalol $(5 \mathrm{mg})$. If the AAI was less than 15 and associated with hypotension, we applied $0.2 \mathrm{mcg} / \mathrm{ml}$ and $0.2 \%$ decrements in propofol and sevoflurane, respectively. If two decrements were unsuccessful, propofol and sevoflurane were decreased by $0.5 \mathrm{mcg} / \mathrm{ml}$ and $0.5 \%$ decrements, respectively, until the AAI was between 15 and 25. Hypotension was treated initially with fluids and $4 \mathrm{mg}$ ephedrine was given intravenously if the AAI was in the set range. Atropine $(0.5 \mathrm{mg})$ was given if the HR decreased to $<50$ beats/min and was accompanied by hypotension.

Respiratory frequency and end-tidal volume were adjusted to maintain the $\mathrm{ETCO}_{2}$ at $32-35 \mathrm{mmHg}$. The i.v. fluid administration during operation in each patient was calculated on the basis of body weight, fasting time, blood loss, and maintenance fluid requirement. One hour following the initial dose of cisatracurium, muscle relaxation was maintained with cisatracurium $0.03 \mathrm{mg} / \mathrm{kg} / 30 \mathrm{~min}$ i.v. as a bolus dose, until 30 min before emergence. At the last 10 stitches of surgery, administration of the maintenance anesthetics was discontinued and the oxygen flow was adjusted to $6 \mathrm{l} / \mathrm{min}$. Muscle relaxation was reversed with intravenous neostigmine $(2.5 \mathrm{mg})$ combined with atro- pine (1 mg). Extubation was performed with RR less than 25 breaths/min, spontaneous tidal volume greater than $5 \mathrm{ml} / \mathrm{kg}$, inspiratory force of at least $-20 \mathrm{~cm} \mathrm{H}_{2} \mathrm{O}$, vital capacity at least $10 \mathrm{ml} / \mathrm{kg}$, and the ability of the patient to open the eyes by verbal command. Emergence from anesthesia was assessed by measuring the time until removal of the endotracheal tube.

\section{Measurement protocol}

\section{Preoperative measurements}

A research nurse recorded the baseline characteristics of consenting patients, including information on age, height, weight, and general health.

\section{Intraoperative measurements}

Intraoperatively, the following data were recorded: Doses and duration of induction, type and doses of all the medication administered intraoperatively, total amount of perioperative fluid, and surgical time. Time to awakening (response to verbal command) and time to extubation after discontinuation of anesthesia were recorded.

\section{Postoperative measurements}

Time to permission for discharge from the PACU was recorded. The intensity of pain was assessed using a visual analogue scale (VAS) based on a total score between 0 and $10(0=$ no pain and $10=$ worst pain $)$. If the intensity of postoperative pain was more than 4 , ketorolac $30 \mathrm{mg}$ was immediately given intravenously. Approximately $24 \mathrm{~h}$ after surgery, another member of the nursing staff who was unaware of the study visited inpatients in the ward to record the occurrence of PONV and the presence of possible postoperative side effects subsequent to discharge from the PACU. Total admission days were also recorded.

\section{Statistical analysis}

The sample size was calculated using G-power 3.1.2 software. A pilot study of 15 cases per group suggested $13 \%$ and $40 \%$ of PONV rates in TIVA and SEVO groups, respectively. A power calculation $(\alpha=0.05$ and $\beta=0.2)$ indicated that a minimum sample size of 41 patients for each group would be necessary to achieve the desired level of statistical power.

Data were analyzed using the SPSS version 19.0 for Windows (SPSS Inc., Chicago, IL, USA). Continuous data were analyzed using two-sample $t$-test. Discrete data were analyzed using Pearson's Chi-square or Fisher's exact tests. In all cases, a $p<0.05$ was considered to be statistically significant. 


\section{RESULTS}

\section{Baseline characteristics and intraoperative data}

In total, 84 patients were recruited to participate in the study. There were no significant differences in demogr aphic characteristics between the two groups [Table 1]. There were also no significant differences between the groups in terms of hemodynamics, blood loss, or AEP levels (data not shown). Table 2 shows the intraoperative data. There were no statistically significant differences in the intubation time, duration of surgery, perioperative fluid management, and extubation time after TIVA or sevoflurane. The time for which the patients stayed at the PACU was similar between the two groups. Table 3 shows the amounts of intraoperative anesthetic drugs used in the two groups. There were no significant differences between the groups in the amounts of muscle relaxants and opioids used.

\section{Postoperative data}

Table 4 shows the postoperative side effects after general anesthesia in the two groups. The cumulative 24-h incidence of PONV was significantly less frequent in the TIVA group, which was only $14.3 \%$ of patients in the TIVA group compared with $50 \%$ patients in the SEVO group. We separated PONV into postoperative nausea or vomiting. Whether postoperative nausea or postoperative vomiting, the incidence was less frequent in the TIVA group than in the SEVO group. There was no significant difference between the groups in the requirements of postoperative analgesic agents. The total cost of anesthetic drugs was significantly higher in the SEVO group [Table 5].

\section{DISCUSSION}

A number of studies have compared general anesthesia with i.v. propofol and sevoflurane. ${ }^{[4-6,16-21]}$ Previous studies were performed for different types of surgery ${ }^{[5,16,21,22]}$ and in difference patient groups. ${ }^{[4,6,7,20]}$ Patients undergoing breast surgery generally have a very high incidence of postoperative nausea or vomiting. ${ }^{[13,15]}$ Here, we applied AEP monitoring as a guide to titrate the level of anesthesia. AEP monitoring was more precise than in previous studies that used titrate analysis of the different anesthetics according to the hemodynamic responses to pain during anesthesia, and therefore, it is easy to err on maintaining the patients deeply anesthetized, which in turn affects recovery. ${ }^{[19]}$ Thus, this study was designed to compare TIVA propofol with inhalational anesthesia under AEP monitoring in female patients undergoing breast surgery.

The primary clinical outcome that differed signifi-
Table 1: Patient characteristics

\begin{tabular}{lccc}
\hline & TIVA $(n=42)$ & Sevo $(n=42)$ & $p$ value \\
\hline ASA physical status & & & 0.79 \\
I & $10(23.8)$ & $9(21.4)$ & \\
II & $32(76.2)$ & $33(78.6)$ & \\
Female gender & $42(100)$ & $42(100)$ & \\
Age $($ years $)$ & $51.17 \pm 9.09$ & $48.67 \pm 10.10$ & 0.24 \\
Height $(\mathrm{cm})$ & $157.52 \pm 4.91$ & $156.86 \pm 5.84$ & 0.56 \\
Weight $(\mathrm{kg})$ & $60.52 \pm 10.45$ & $57.64 \pm 8.51$ & 0.17 \\
BMI $\left(\mathrm{kg} / \mathrm{m}^{2}\right)$ & $24.43 \pm 4.24$ & $23.54 \pm 4.08$ & 0.34 \\
\hline
\end{tabular}

ASA status and gender are shown as the number of patients followed by rounded percentages in parenthesis and analyzed using Pearson's Chi-square test. Age, height, weight, and BMI are shown as mean \pm SD and analyzed using two-sample $t$-test. There are no significant differences in patient characteristics between the two groups, Abbreviations: TIVA group: Total intravenous anesthesia with propofol; SEVO group: Inhalational anesthesia with sevoflurane and propofol induction; ASA: American society of anesthesia; BMI: Body mass index

Table 2: Intraoperative and postoperative data

\begin{tabular}{lccc}
\hline & TIVA $(n=42)$ & Sevo $(n=42)$ & $p$ value \\
\hline Intubation time $(\mathrm{min})$ & $3.95 \pm 1.09$ & $3.79 \pm 1.29$ & 0.51 \\
Surgical duration $(\mathrm{min})$ & $122.02 \pm 45.86$ & $142.57 \pm 46.23$ & 0.06 \\
$\begin{array}{l}\text { Extubation time (min) } \\
\text { Perioperative fluid }\end{array}$ & $13.38 \pm 6.78$ & $13.02 \pm 5.26$ & 0.81 \\
management (ml) & $1274 \pm 661$ & $1383 \pm 554$ & 0.42 \\
$\begin{array}{lcc}\text { PAR time (min) } \\
\text { Length of hospital stay }\end{array}$ & $83.02 \pm 10.55$ & $88.52 \pm 15.21$ & 0.07 \\
(days) & $3.36 \pm 1.19$ & $4.60 \pm 1.20$ & $<0.001$ \\
\hline All & & &
\end{tabular}

All values are presented as mean $\pm \mathrm{SD}$ and analyzed using two-sample $t$-test, Abbreviations: Time to intubation: Time from induction until successful insertion of the endotracheal tube; Time to extubation: Time from discontinuation of anesthesia until response to a verbal command and removal of the endotracheal tube; TIVA group: Total intravenous anesthesia with propofol; SEVO group: Inhalational anesthesia with sevoflurane and propofol induction

Table 3: Amount of intraoperative anesthetic drugs used in the two groups

\begin{tabular}{lccc}
\hline & TIVA $(n=42)$ & Sevo $(n=42)$ & $p$ value \\
\hline Fentanyl $(\mathrm{ml})$ & $3.40 \pm 0.80$ & $3.36 \pm 0.66$ & 0.77 \\
Fentanyl $(\mathrm{mcg})$ & $170.24 \pm 39.91$ & $167.86 \pm 32.80$ & 0.77 \\
Cisatracurium $(\mathrm{PC})$ & $2.12 \pm 0.50$ & $2.02 \pm 0.35$ & 0.31 \\
Cisatracurium $(\mathrm{mg})$ & $17.43 \pm 5.30$ & $15.64 \pm 3.38$ & 0.07 \\
Propofol $(\mathrm{PC})$ & $7.71 \pm 3.24$ & $1 \pm 0.00$ & - \\
Including wastage & & & \\
Sevoflurane (ml) & - & $32.9 \pm 11.46$ & -
\end{tabular}

Values are shown as mean \pm SD, There were no significant differences between the groups in the amounts of muscle relaxants and opioids used, Abbreviations: TIVA group: Total intravenous anesthesia with propofol; SEVO group: Inhalational anesthesia with sevoflurane and propofol induction

cantly between groups was postoperative nausea or vomiting, which was more frequent in patients who received sevoflurane for maintenance of anesthesia and less frequent 
Table 4: Postoperative complications in the two anesthetic groups

\begin{tabular}{lccc}
\hline & TIVA $(n=42)$ & Sevo $(n=42)$ & $p$ value \\
\hline PONV & $6(14.3)$ & $21(50.0)$ & $<0.001$ \\
Nausea & $3(7.1)$ & $15(35.7)$ & 0.001 \\
Vomiting & $5(11.9)$ & $14(33.3)$ & 0.019 \\
Required NSAID & $4(9.5)$ & $3(7.1)$ & 0.697 \\
analgesic at PACU & & &
\end{tabular}

All values are presented as the number (\%) of occurrences, These data were analyzed using Pearson's Chi-square test, Abbreviations: PONV: Postoperative nausea and vomiting; NSAID: Nonsteroidal anti-inflammatory drug; PACU: Post-anesthetic care unit; TIVA group: Total intravenous anesthesia with propofol; SEVO group: Inhalational anesthesia with sevoflurane and propofol induction

Table 5: Basic cost assumptions for the economic analyses

\begin{tabular}{lcc}
\hline Drug acquisition costs & NTD \\
\hline Propofol $1 \%(20 \mathrm{ml})$ & 57 \\
Sevoflurane $(250 \mathrm{ml})$ & 4305 \\
Fentanyl $(10 \mathrm{ml})$ & 98 \\
Cisatracurium $(5 \mathrm{ml})$ & & 92 \\
\hline Cost analysis & TIVA $(n=42)$ & Sevo $(n=42)$ \\
\hline Cost of propofol (NTD) & $439 \pm 185$ & 57 \\
Including wastage & - & $567 \pm 197$ \\
Cost of Sevoflurane (NTD) & $-648 \pm 185$ & $850 \pm 197$ \\
Total cost (NTD) & &
\end{tabular}

All values are shown as mean \pm SD, Abbreviations: TIVA group: Total intravenous anesthesia with propofol; SEVO group: Inhalational anesthesia with sevoflurane and propofol induction; NTD: New Taiwan dollars

in those receiving propofol. Similar findings have been reported previously, ${ }^{[4]}$ and the results are compatible with the suspected antiemetic effects of propofol. Nonetheless, propofol was recently found to possess direct antiemetic properties, and this effect is not due to the intralipid emulsion in the formulation of propofol. ${ }^{[23]}$ Several studies found a low incidence of PONV when propofol was used throughout the procedure. ${ }^{[24-28]}$ The protective effect of propofol against PONV seemed to disappear when it was used as an induction agent only. ${ }^{[29,30]}$ Thus, it is possible that a therapeutic range of plasma concentrations of propofol may be related to PONV protection.

Some studies suggest that an increase of opioids increases the risk of nausea and vomiting. ${ }^{[31,32]}$ However, the mechanisms of opioids are complex. ${ }^{[33]}$ Low-dose opioids for induction of anesthesia ( $1.5 \mathrm{mcg} / \mathrm{kg}$ fentanyl) led only to a small increase in PONV incidence, and the increase was not statistically significant. ${ }^{[34]}$ Therefore, further research in this field is warranted to clarify this issue. While data on the impacts of opioids given intraoperatively are controversial, several studies suggest that the use of postoperative opioids increases the risk of PONV. ${ }^{[15,34,35]}$ Thus, we chose nonsteroidal anti-inflammatory drugs (if the intensity of postoperative pain was more than VAS 4, ketorolac $30 \mathrm{mg}$ was immediately given intravenously) as postoperative analgesic agents, which have been shown to decrease PONV, compared with opioids, in numerous studies. $^{[36,37]}$

Another important finding was that extubation times were similar in the TIVA group and the SEVO group (13.38 vs. $13.02 \mathrm{~min}$, respectively). The end-tidal sevoflurane concentration of tracheal extubation was $0.33 \pm 0.10 \%$, which was not different from that observed in our clinical practice. Several studies have claimed that patients who received sevoflurane were extubated at an earlier stage than those receiving propofol, and the times to eye opening were also shorter ${ }^{[6,16]}$ This difference can be explained in part by the proximity of AEP which could monitor anesthetic depth. The use of APE may improve the ability of anesthesiologists to titrate anesthetic drugs and contribute to a faster recovery from general anesthesia. ${ }^{[38]}$

There is a limitation that needs to be acknowledged and addressed regarding the present study. Although there were no significant differences between the groups in terms of surgical duration $(p=0.06)$ in our study, duration of surgery is a known relative predictor for PONV, with the risk increasing proportionately after $90 \mathrm{~min} \cdot{ }^{[39,40]}$ Therefore, additional studies on the side effects of patients undergoing breast surgery are clearly needed to determine the role of the duration of surgery in clinical practice.

In addition, in the era of economic management of health care, it is necessary to identify the best and most cost-effective anesthetic techniques. At the same time, cost control is of major importance in today's climate of economic consciousness and the choice of anesthetic can have a significant impact on the total costs for an anesthesia department. We have shown the direct cost of sevoflurane used in the maintenance of anesthesia to be significantly higher than that of a propofol-based anesthetic [Table 5], while achieving a similar outcome in terms of emergent and recovery times [Table 2]. The higher incidence of PONV in the inhalational anesthetic group may also have increase the indirect costs ${ }^{[17]}$ as the management of vomiting may involve using more disposable items (e.g., bowls, bedding, etc.). PONV may increase recovery staff activities, but this is unlikely to increase the costs unless the number of staff required is altered. PONV also significantly delays discharge times, and therefore, propofol-based anesthesia could shorten the duration of stay, therefore reducing the direct costs. ${ }^{[17]}$

In conclusion, when compared with sevoflurane, we have shown that propofol used for the maintenance of general anesthesia improves postoperative patient well-being and reduces the incidence of PONV. Furthermore, total i.v. anesthesia with propofol also reduces costs. Thus, total i.v. anesthesia with propofol is better than sevoflu- 
rane anesthesia for patients undergoing breast surgery in our study.

\section{REFERENCES}

1. Beinlich I. Anesthesia-related morbidity and mortality. Anasthesiol Intensivmed Notfallmed Schmerzther 1991;26:177-85.

2. Boucher BA, Witt WO, Foster TS. The postoperative adverse effects of inhalational anesthetics. Heart Lung 1986;15:63-9.

3. Fish WH, Hobbs AJ, Daniels MV. Comparison of sevoflurane and total intravenous anaesthesia for daycase urological surgery. Anaesthesia 1999;54:1002-6.

4. Fredman B, Nathanson MH, Smith I, Wang J, Klein K, White PF. Sevoflurane for outpatient anesthesia: A comparison with propofol. Anesth Analg 1995;81:823-8.

5. Godet G, Watremez C, El Kettani C, Soriano C, Coriat P. A comparison of sevoflurane, target-controlled infusion propofol, and propofol/isoflurane anesthesia in patients undergoing carotid surgery: A quality of anesthesia and recovery profile. Anesth Analg 2001;93:560-5.

6. Jellish WS, Lien CA, Fontenot HJ, Hall R. The comparative effects of sevoflurane versus propofol in the induction and maintenance of anesthesia in adult patients. Anesth Analg 1996;82:479-85.

7. Joo HS, Perks WJ. Sevoflurane versus propofol for anesthetic induction: A meta-analysis. Anesth Analg 2000;91:213-9.

8. Sneyd JR, Carr A, Byrom WD, Bilski AJ. A meta-analysis of nausea and vomiting following maintenance of anaesthesia with propofol or inhalational agents. Eur J Anaesthesiol 1998;15:433-45.

9. Borgeat A, Wilder-Smith $\mathrm{OH}$, Wilder-Smith $\mathrm{CH}$, Forni M, Suter PM. Propofol improves patient comfort during cisplatin chemotherapy. A pilot study. Oncology 1993;50:456-9.

10. Borgeat A, Wilder-Smith OH, Saiah M, Rifat K. Subhypnotic doses of propofol possess direct antiemetic properties. Anesth Analg 1992;74:539-41.

11. Gan TJ, El-Molem H, Ray J, Glass PS. Patient-controlled antiemesis: A randomized, double-blind comparison of two doses of propofol versus placebo. Anesthesiology 1999;90:1564-70.

12. Reihner E, Grunditz R, Giesecke K, Gustafsson LL. Postoperative nausea and vomiting after breast surgery: Efficacy of prophylactic ondansetron and droperidol in a randomized placebo-controlled study. Eur J Anaesthesiol 2000;17:197-203.

13. Oddby-Muhrbeck E, Jakobsson J, Andersson L, Askergren J. Postoperative nausea and vomiting. A comparison between intravenous and inhalation anaesthesia in breast surgery. Acta Anaesthesiol Scand 1994;38:52-6.

14. Purkis IE. Factors that influence postoperative vomiting. Can Anaesth Soc J 1964;11:335-53.

15. Cohen MM, Duncan PG, DeBoer DP, Tweed WA. The postoperative interview: Assessing risk factors for nausea and vomiting. Anesth Analg 1994;78:7-16.

16. Raeder J, Gupta A, Pedersen FM. Recovery characteristics of sevoflurane- or propofol-based anaesthesia for day-care surgery. Acta Anaesthesiol Scand 1997;41:988-94.

17. Smith I, Terhoeve PA, Hennart D, Feiss P, Harmer M, Pourriat JL, et al. A multicentre comparison of the costs of anaesthesia with sevoflurane or propofol. Br J Anaesth 1999;83:564-70.

18. Watson KR, Shah MV. Clinical comparison of 'single agent' anaesthesia with sevoflurane versus target controlled infusion of propofol. Br J Anaesth 2000;85:541-6.

19. Gupta A, Stierer T, Zuckerman R, Sakima N, Parker SD, Fleisher LA. Comparison of recovery profile after ambulatory anesthesia with propofol, isoflurane, sevoflurane and desflurane: A systematic review. Anesth Analg 2004;98:632-41.

20. Sepulveda P, Nunez G, Ramos M, Recart A. Comparison of rapid anesthetic induction with sevoflurane vs target-controlled infusion of propofol. Rev Esp Anestesiol Reanim 2008;55:461-7.

21. Bignami E, Landoni G, Gerli C, Testa V, Mizzi A, Fano G, et al. Sevoflurane vs. propofol in patients with coronary disease undergoing mitral surgery: A randomised study. Acta Anaesthesiol Scand 2012; 56:482-90

22. Lee DW, Lee HG, Jeong CY, Jeong SW, Lee SH. Postoperative nausea and vomiting after mastoidectomy with tympanoplasty: A comparison between TIVA with propofol-remifentanil and balanced anesthesia with sevoflurane-remifentanil. Korean J Anesthesiol 2011;61:399-404.

23. Ostman PL, Faure E, Glosten B, Kemen M, Robert MK, Bedwell S. Is the antiemetic effect of the emulsion formulation of propofol due to the lipid emulsion? Anesth Analg 1990;71:536-40.

24. Price ML, Walmsley A, Swaine C, Ponte J. Comparison of a total intravenous anaesthetic technique using a propofol infusion, with an inhalational technique using enflurane for day case surgery. Anaesthesia 1988;43 Suppl:84-7.

25. Doze VA, Shafer A, White PF. Propofol-nitrous oxide versus thiopental-isoflurane-nitrous oxide for general anesthesia. Anesthesiology 1988;69:63-71.

26. Van HJ, Smith I, White PF. Use of desflurane for outpatient anesthesia. A comparison with propofol and nitrous oxide. Anesthesiology 1991;75:197-203.

27. Randel GI, Levy L, Kothary SP, Pandit SK. Propofol versus thiamylal-enflurane anesthesia for outpatient laparoscopy. J Clin Anesth 1992;4:185-9.

28. Lebenbom-Mansour MH, Pandit SK, Kothary SP, Randel GI, Levy L. Desflurane versus propofol anesthesia: A comparative analysis in outpatients. Anesth Analg 1993;76:936-41.

29. de Grood PM, Harbers JB, van EJ, Crul JF. Anaesthesia for laparoscopy. A comparison of five techniques including propofol, etomidate, thiopentone and isoflurane. Anaesthesia 1987;42:815-23.

30. Chittleborough MC, Osborne GA, Rudkin GE, Vickers D, Leppard PI, Barlow J. Double-blind comparison of patient recovery after induction with propofol or thiopentone for day-case relaxant general anaesthesia. Anaesth Intensive Care 1992;20:169-73.

31. Anderson BJ, Pearce S, McGann JE, Newson AJ, Holford NH. Investigations using logistic regression models on the effect of the LMA on morphine induced vomiting after tonsillectomy. Paediatr Anaesth 2000;10:633-8.

32. Anderson BJ, Ralph CJ, Stewart AW, Barber C, Holford NH. The dose-effect relationship for morphine and vomiting after day-stay tonsillectomy in children. Anaesth Intensive Care 2000;28:155-60.

33. Takahashi T, Tsuchida D, Pappas TN. Central effects of morphine on GI motility in conscious dogs. Brain Res 2007;1166:29-34.

34. Apfel CC, Kranke P, Katz MH, Goepfert C, Papenfuss T, Rauch S, 
et al. Volatile anaesthetics may be the main cause of early but not delayed postoperative vomiting: A randomized controlled trial of factorial design. Br J Anaesth 2002;88:659-68.

35. Tramer MR. Postoperative nausea and vomiting. Anaesthesist 2007;56:679-85.

36. Salman MA, Yucebas ME, Coskun F, Aypar U. Day-case laparoscopy: A comparison of prophylactic opioid, NSAID or local anesthesia for postoperative analgesia. Acta Anaesthesiol Scand 2000;44:536-42.

37. Marret E, Kurdi O, Zufferey P, Bonnet F. Effects of nonsteroidal antiinflammatory drugs on patient-controlled analgesia morphine side effects: Meta-analysis of randomized controlled trials Anesthesiology 2005;102:1249-60.

38. Assareh H, Anderson RE, Uusijarvi J, Jakobsson J. Sevoflurane requirements during ambulatory surgery: A clinical study with and without AEP-index guidance. Acta Anaesthesiol Scand 2002;46:495-9.

39. Marcus JR, Few JW, Chao JD, Fine NA, Mustoe TA. The prevention of emesis in plastic surgery: A randomized, prospective study. Plast Reconstr Surg 2002;109:2487-94.

40. Apfel CC, Roewer N. Risk assessment of postoperative nausea and vomiting. Int Anesthesiol Clin 2003;41:13-32. 